\title{
The effect of losartan therapy on ventricular function in Marfan patients with haploinsufficient or dominant negative FBN1 mutations
}

\author{
A. W. den Hartog ${ }^{1,2}$ - R. Franken ${ }^{1,2} \cdot$ M. P. van den Berg ${ }^{3}$ A. H. Zwinderman ${ }^{2,4} \cdot$ J. Timmermans ${ }^{5}$. \\ A. J. Scholte ${ }^{6}$ V. de Waard ${ }^{7}$ A. M. Spijkerboer ${ }^{8}$ G. Pals ${ }^{9}$ B. J. M. Mulder ${ }^{1,2}$ • M. Groenink ${ }^{1,2,8}$
}

Published online: 4 October 2016

(C) The Author(s) 2016. This article is available at SpringerLink with Open Access.

\begin{abstract}
Background Mild biventricular dysfunction is often present in patients with Marfan syndrome. Losartan has been shown to reduce aortic dilatation in patients with Marfan syndrome. This study assesses the effect of losartan on ventricular volume and function in genetically classified subgroups of asymptomatic Marfan patients without significant valvular regurgitation.

Methods In this predefined substudy of the COMPARE study, Marfan patients were classified based on the effect of their FBN1 mutation on fibrillin-1 protein, categorised
\end{abstract}

M. Groenink

m.groenink@amc.uva.nl

1 Department of Cardiology, Academic Medical Center Amsterdam, Rm. F3-147, Meibergdreef 9, 1105 AZ Amsterdam, The Netherlands

2 Institute of the Netherlands, Interuniversity Cardiology, Utrecht, The Netherlands

3 Department of Cardiology, University Medical Center Groningen, Groningen, The Netherlands

4 Department of Clinical Epidemiology and Biostatistics, Academic Medical Center Amsterdam, Amsterdam, The Netherlands

5 Department of Cardiology, Radboud University Medical Center Nijmegen, Nijmegen, The Netherlands

6 Department of Cardiology, Leiden University Medical Center, Leiden, The Netherlands

7 Department of Medical Biochemistry, Academic Medical Center Amsterdam, Amsterdam, The Netherlands

8 Department of Radiology, Academic Medical Center Amsterdam, Amsterdam, The Netherlands

9 Department of Clinical Genetics, VU University Medical Center, Amsterdam, The Netherlands as haploinsufficient or dominant negative. Patients were randomised to a daily dose of losartan $100 \mathrm{mg}$ or no additional treatment. Ventricular volumes and function were measured by magnetic resonance imaging at baseline and after 3 years of follow-up.

Results Changes in biventricular dimensions were assessed in 163 Marfan patients (48\% female; mean age $38 \pm 13$ years). In patients with a haploinsufficient FBN1 mutation $(n=43)$, losartan therapy $(n=19)$ increased both biventricular end diastolic volume (EDV) and stroke volume (SV) when compared with no additional losartan $(n=24)$ : left ventricular EDV: $9 \pm 26 \mathrm{ml}$ vs. $-8 \pm 24 \mathrm{ml}$, $p=0.035$ and right ventricular EDV $12 \pm 23 \mathrm{ml}$ vs. $-18 \pm$ $24 \mathrm{ml} ; p<0.001$ and for left ventricle SV: $6 \pm 16 \mathrm{ml} \mathrm{vs}$. $-8 \pm 17 \mathrm{ml} ; p=0.009$ and right ventricle $\mathrm{SV}: 8 \pm 16 \mathrm{ml}$ vs. $-7 \pm 19 \mathrm{ml} ; p=0.009$, respectively. No effect was observed in patients with a dominant negative FBN1 mutation ( $n=$ 92), or without an FBN1 mutation $(n=28)$.

Conclusion Losartan therapy in haploinsufficient Marfan patients increases biventricular end diastolic volume and stroke volume, furthermore, losartan also appears to ameliorate biventricular filling properties.

Keywords Marfan syndrome - Ventricular function · Ventricular volumes · Losartan · Cardiac magnetic resonance imaging · FBN1 mutation classes

\section{Introduction}

Marfan syndrome (MFS) is caused by mutations in the $F B N 1$ gene, leading to deficiency (haploinsufficient $\{\mathrm{HI}\}$ mutations) or malformation (dominant-negative $\{\mathrm{DN}\} \mathrm{mu}-$ tations) of the fibrillin-1 protein [1], ultimately leading to aortic dilatation and dissection [2-4]. Treatment with losar- 
tan, an angiotensin-II receptor-1 blocker (ARB), has been shown to have a beneficial effect on aortic pathology in MFS murine models. Human MFS studies on aortic dilatation rate have demonstrated conflicting results [5-7], however, losartan may have a beneficial effect in patients with an HI mutation.

Although a mild biventricular dysfunction is often present in MFS patients without significant valvular pathology [8-12], the effect of losartan on cardiac dimensions and function in MFS patients is still unknown. Here, we assess the effect of losartan on left and right ventricular dimensions and function in both HI and DN asymptomatic MFS patients without significant valvular regurgitation by cardiac magnetic resonance imaging (CMR).

\section{Methods}

\section{Patients}

All study subjects were participants in the multicentre, randomised COMPARE trial $[5,13]$. In short, the COMPARE trial was designed to investigate the effect of losartan on the aortic dilatation rate in adult MFS patients. Patients ( $\geq 18$ years) fulfilling the Ghent criteria of 1996 were included [14]. Exclusion criteria were: (A) treatment with angiotensin-converting-enzyme inhibitor (ACEi) or ARB before study entry, (B) an aortic root diameter $>50 \mathrm{~mm}$, (C) a history of aortic dissection, and (D) $\geq 1$ vascular prosthesis. For the current predefined study, (E) only patients fulfilling the revised Ghent criteria of 2010 [15] were included, and (F) patients with moderate to severe valvular regurgitation were excluded [16]. All previously prescribed medication, including $\beta$-blockers and calcium channel blockers, was continued during the study. Written informed consent was obtained from all participants. The study protocol conforms to the ethical guidelines of the 1975 Declaration of Helsinki and was approved by the institution's human research committee. All patients gave their informed consent.

\section{Mutation classification}

To detect mutations, sanger sequencing of the 65 coding $F B N 1$ exons in genomic DNA was used. Mutations were classified into two groups according to the effect of the mutation on the fibrillin-1 protein [17]. Patients with a DN effect were defined as having mutations leading to production of malfunctional fibrillin-1 protein. DN mutations included: (1) missense mutations leading to stable mutant fibrillin-1 protein; (2) mutations leading to exon skipping or deletion resulting in in-frame events [18]; and (3) prema- ture termination codon mutations leading to a shorter but stable fibrillin-1 protein ( $>10$ exons).

An HI effect of the FBN1 mutation was defined as a mutation leading to a reduced amount of normal fibrillin-1 protein [19-21] as predicted by the Alamut ${ }^{\circledR}$ software (Interactive Biosoftware, Rouen, France) [21]. HI mutations included: (1) deletion of the whole FBN1 gene; (2) deletion of at least the first or last exon; (3) premature termination codon mutations leading to nonsense mediated decay or to a very short truncated protein (translation $<10$ exons of the FBN1 gene) [22]; and (4) missense mutations leading to degradation of the protein [23].

\section{Medication}

Participating patients started on losartan treatment after baseline examinations. Patients were randomly assigned to a 1:1 ratio to receive losartan daily (losartan group), or to no additional treatment (control group). Target dosage was $100 \mathrm{mg}$ losartan daily.

\section{Magnetic resonance imaging}

At baseline and after 3 years of follow-up, CMR imaging of the right and left ventricle was performed. All CMR scans were performed at two centres (Academic Medical Center Amsterdam and Leiden University Medical Center). To obtain ventricular volumes, magnetic resonance imaging was performed with either an Avanto (Siemens, Erlangen, Germany), or a Philips (Intera, release 11 and 12; Philips Medical Systems, Best, the Netherlands) 1.5 T MRI scanner using a phased array cardiac receiver coil. ECG-gated cine images were acquired during breath-hold using a segmented, steady-state, free-precession sequence. Short-axis views were obtained every $10 \mathrm{~mm}$, starting from the base up to the apex and covering the entirety of both ventricles. Additionally, flow (m/s) through the aortic root and ascending aorta was assessed by phase contrast velocity mapping to rule out significant valvular regurgitation, unnoticed at prior echocardiography.

\section{Image analysis}

The primary endpoint of this study was change in left and right ventricular volumes and systolic function after 3 years of follow-up measured by CMR. All measurements were performed using $\mathrm{MASS}^{\circledR}$ and ${ }^{\mathrm{FLOW}}{ }^{\circledR}$ image analysis software (Medis, Leiden, the Netherlands) by a single observer $(\mathrm{AWdH})$ under the supervision of an experienced cardiologist (MG) and radiologist (AMS) with no prior knowledge of patients' medical therapy.

Endocardial contours of the left and right ventricle were manually traced in end systole and end diastole on all short- 


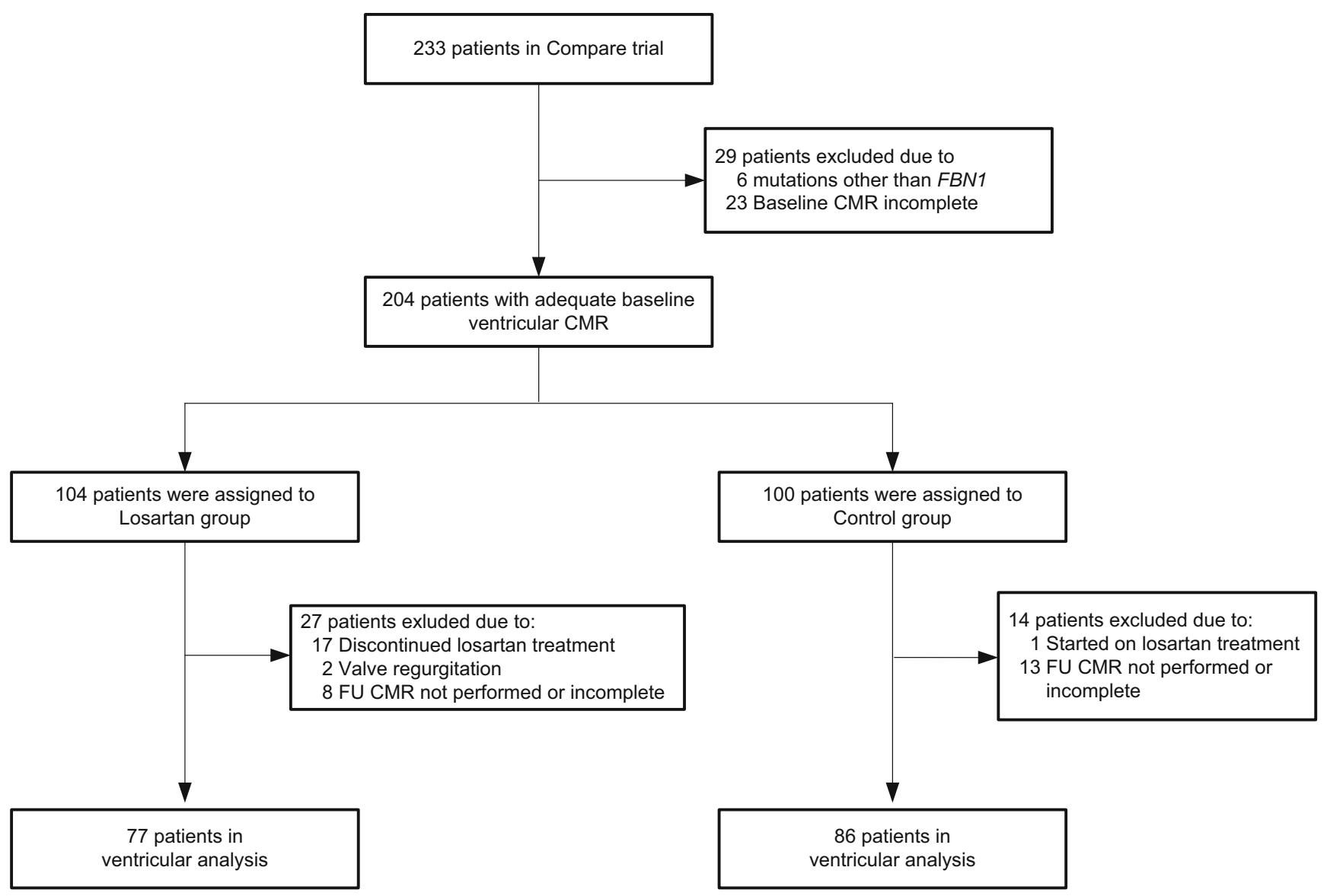

Fig. 1 Randomisation and follow-up for ventricular function analysis. Abbreviations: $C M R$ denotes cardiac magnetic resonance, $F U$ denotes follow-up

axis images. End diastole was defined as the phase with the largest ventricular area and end systole as the phase with the smallest ventricular area. Left ventricular (LV) and right ventricular (RV) end diastolic volume (EDV), end systolic volume (ESV) and stroke volume (SV = EDV-ESV) were determined. Left and right ventricular ejection fraction (EF) was calculated $(E F=S V / E D V)$. Flow through the aorta was calculated using manually drawn areas on the modulus images and the velocity values of the corresponding velocity encoded images by using flow image analysis software (Flow ${ }^{\circledR}$, Medis, Leiden, the Netherlands). Severity of valvular regurgitation was assessed quantitatively by $\mathrm{CMR}$ in accordance with $\mathrm{ACC} / \mathrm{AHH}$ guidelines for the management of patients with valvular heart disease [16]. Moderate to severe valvular regurgitation was defined as regurgitant volume of $\geq 30 \mathrm{ml}$ per beat or a regurgitant fraction of $\geq 30 \%$ [16]. a dilated ventricle was assumed to exceed an EDV of $97 \mathrm{ml} / \mathrm{m}^{2}$ [24].

\section{Statistical analysis}

Data are presented as mean value \pm standard deviation and categorical variables as numbers and percentages. Be- tween-group comparisons of quantitative and categorical variables were made by Students' t-test and Fisher's exact tests, respectively. Associations between characteristics were explored with regression analysis. The effect of losartan on change in ventricular volumes and function was evaluated by the two-tailed Student's t-tests. All analyses were per protocol analyses in order to evaluate the change in ventricular volumes between the two groups of MFS patients who continued their losartan treatment throughout the entire study, and those in whom losartan treatment was not started during the study. a two-tailed $P<0.05$ was considered statistically significant. For statistical analyses, PASW 19.0 (SPSS Inc., Chicago, IL) for Windows (Microsoft, Redmond, WA) was used.

\section{Results}

\section{Patients}

Patient recruitment and characteristics have been described in detail previously [5]. (17)In the COMPARE trial, a total of 233 MFS patients were included between January 
2008 and December 2009 [5]. Change in cardiac function was assessed in 163 patients ( $48 \%$ female, mean age $38 \pm 13$ years, Fig. 1). a pathogenic FBNl mutation was found in 135 patients $(83 \%)$. In patients with a known FBN1 mutation, 92 patients (68\%) had a DN FBN1 mutation and 43 patients (32\%) had an HI FBN1 mutation. No FBN1 mutation could be found in 28 patients. a total of 77 MFS patients were randomised to losartan treatment, while 86 MFS patients received no additional treatment. The remaining cardiovascular medicinal treatment did not change during follow-up.

Baseline characteristics between the treatment groups were comparable with the exception of body surface area (BSA) and heart rate in HI patients (Table 1).

Left ventricular EF in DN patients was lower than the EF in HI patients, $51 \pm 7 \%$ vs. $53 \pm 4 \%, p=0.013$. The remaining ventricular characteristics were comparable between the groups, including the frequency of a dilated ventricle $26 \%$ vs. $23 \%, p=0.724$, respectively.

\section{Losartan and ventricular function in mutational subgroups}

After a mean of $3.1 \pm 0.4$ years of follow-up, the biventricular EDV increased in HI patients on losartan therapy $(n=19)$ compared with HI controls $(n=24)$ : LV-EDV: $9 \pm$ $26 \mathrm{ml}$ vs. $-8 \pm 24 \mathrm{ml} ; p=0.035$ and RV-EDV $12 \pm 23 \mathrm{ml}$ vs. $-18 \pm 24 \mathrm{ml} ; p<0.001$, respectively. Similar results were seen in RV-ESV, however, not in LV-ESV (Table 2). In HI patients on losartan therapy, the increase in biventricular EDV was accompanied by an increase in SV, for LV-SV: $6 \pm 16 \mathrm{ml}$ vs. $-8 \pm 17 \mathrm{ml} ; p=0.009$ and RV-SV: $8 \pm 16 \mathrm{ml}$ vs. $-7 \pm 19 \mathrm{ml} ; p=0.009$, respectively (Table 2, Fig. 2). No effect of losartan was observed in patients with a DN FBNI mutation or without an FBNI mutation. No effect of losar-

Table 1 Baseline characteristics of 163 patients with Marfan syndrome

\begin{tabular}{|c|c|c|c|c|c|c|}
\hline \multirow[t]{2}{*}{ Characteristics } & \multicolumn{3}{|l|}{ Losartan } & \multicolumn{3}{|c|}{ No losartan } \\
\hline & No FBN1 & $\mathrm{DN}$ & $\mathrm{HI}$ & No FBN1 & $\mathrm{DN}$ & $\mathrm{HI}$ \\
\hline Number of patients & 16 & 42 & 19 & 12 & 50 & 24 \\
\hline Age (years) & $39 \pm 13$ & $36 \pm 12$ & $33 \pm 10$ & $44 \pm 12$ & $39 \pm 14$ & $37 \pm 13$ \\
\hline Male $(\%)$ & $9(56)$ & $23(55)$ & $10(53)$ & $6(50)$ & $24(48)$ & $13(54)$ \\
\hline $\operatorname{BSA}\left(\mathrm{m}^{2}\right)$ & $2.0 \pm 0.2$ & $2.0 \pm 0.2$ & $2.0 \pm 0.2^{*}$ & $1.9 \pm 0.4$ & $2.0 \pm 0.2$ & $2.1 \pm 0.2^{*}$ \\
\hline MAP $(\mathrm{mm} \mathrm{Hg})$ & $93 \pm 13$ & $91 \pm 11$ & $91 \pm 11$ & $87 \pm 13$ & $90 \pm 9$ & $90 \pm 8$ \\
\hline Heartrate (bpm) & $67 \pm 11$ & $68 \pm 13$ & $67 \pm 14^{*}$ & $68 \pm 15$ & $66 \pm 11$ & $61 \pm 6^{*}$ \\
\hline Aortic root diameter (mm) & $45 \pm 6$ & $44 \pm 5$ & $44 \pm 6$ & $42 \pm 3$ & $45 \pm 5$ & $43 \pm 5$ \\
\hline Aortic root replacement $(\%)$ & $4(25)$ & $6(14)$ & $5(26)$ & $7(58)$ & $16(32)$ & $5(21)$ \\
\hline Mitral valve surgery $(\%)$ & $1(6)$ & 0 & 0 & 0 & $4(8)$ & 0 \\
\hline \multicolumn{7}{|l|}{ Valve dysfunction } \\
\hline$\geq$ moderate $\mathrm{AR}(\%)$ & 0 & 0 & $1(3)$ & 0 & 0 & 0 \\
\hline$\geq$ moderate MR $(\%)$ & 0 & 0 & $1(3)$ & 0 & 0 & 0 \\
\hline$\geq$ moderate $\mathrm{TR}(\%)$ & 0 & 0 & 0 & 0 & 0 & 0 \\
\hline$\geq$ moderate $\mathrm{PR}(\%)$ & 0 & 0 & 0 & 0 & 0 & 0 \\
\hline \multicolumn{7}{|l|}{ Medication } \\
\hline$\beta$-blocker use $(\%)$ & $13(81)$ & $31(74)$ & $14(74)$ & $9(75)$ & $36(72)$ & $14(58)$ \\
\hline \multicolumn{7}{|l|}{ Left Ventricular } \\
\hline $\mathrm{ESV} / \mathrm{BSA}\left(\mathrm{ml} / \mathrm{m}^{2}\right)$ & $39 \pm 9$ & $42 \pm 11$ & $42 \pm 10$ & $44 \pm 13$ & $44 \pm 14$ & $39 \pm 9$ \\
\hline $\mathrm{EDV} / \mathrm{BSA}\left(\mathrm{ml} / \mathrm{m}^{2}\right)$ & $81 \pm 14$ & $86 \pm 18$ & $87 \pm 17$ & $89 \pm 19$ & $88 \pm 18$ & $86 \pm 15$ \\
\hline $\mathrm{SV} / \mathrm{BSA}\left(\mathrm{ml} / \mathrm{m}^{2}\right)$ & $43 \pm 8$ & $44 \pm 10$ & $45 \pm 9$ & $45 \pm 8$ & $44 \pm 7$ & $46 \pm 8$ \\
\hline $\mathrm{EF}(\%)$ & $53 \pm 7$ & $51 \pm 6$ & $52 \pm 4$ & $52 \pm 6$ & $50 \pm 7$ & $54 \pm 5$ \\
\hline \multicolumn{7}{|l|}{ Right Ventricular } \\
\hline $\mathrm{ESV} / \mathrm{BSA}\left(\mathrm{ml} / \mathrm{m}^{2}\right)$ & $45 \pm 12$ & $40 \pm 12$ & $41 \pm 10$ & $43 \pm 11$ & $42 \pm 16$ & $40 \pm 10$ \\
\hline $\mathrm{EDV} / \mathrm{BSA}\left(\mathrm{ml} / \mathrm{m}^{2}\right)$ & $86 \pm 19$ & $82 \pm 18$ & $83 \pm 14$ & $86 \pm 18$ & $84 \pm 19$ & $85 \pm 13$ \\
\hline $\mathrm{SV} / \mathrm{BSA}\left(\mathrm{ml} / \mathrm{m}^{2}\right)$ & $41 \pm 9$ & $42 \pm 8$ & $42 \pm 7$ & $43 \pm 9$ & $42 \pm 7$ & $45 \pm 7$ \\
\hline $\mathrm{EF}(\%)$ & $48 \pm 5$ & $52 \pm 7$ & $51 \pm 5$ & $50 \pm 6$ & $51 \pm 8$ & $53 \pm 7$ \\
\hline
\end{tabular}

$B S A$ Body Surface Area, MAP Mean Arterial Pressure, AR Aortic Regurgitation, $M R$ Mitral Regurgitation, TR Tricuspid Regurgitation, $P R$ Pulmonary Regurgitation, ESV End Systolic Volume, EDV End Diastolic Volume, SV Stroke Volume, EF Ejection Fraction, CI Cardiac Index, DN Dominant Negative FBN1 mutation, HI Haploinsufficient FBN1 mutation

Plus-minus values are means \pm SD

${ }^{*} p<0.005$ for BSA and Heartrate in HI patients between treatment groups 
Table 2 The effect of losartan on left and right ventricle volume and function in Marfan patients with a FBN1 mutation leading to haploinsufficiency or a dominant-negative effect during 3 years of follow-up

\begin{tabular}{|c|c|c|c|c|c|c|}
\hline & \multicolumn{3}{|c|}{ Haploinsufficiency } & \multicolumn{3}{|c|}{ Dominant Negative } \\
\hline & Losartan & No losartan & $p$-value & Losartan & No losartan & $p$-value \\
\hline Number of patients & 19 & 24 & - & 42 & 50 & - \\
\hline$\Delta \mathrm{MAP}(\mathrm{mm} \mathrm{Hg})$ & $-3 \pm 8$ & $-4 \pm 9$ & 0.684 & $-8 \pm 10$ & $-2 \pm 8$ & 0.003 \\
\hline$\Delta \mathrm{HR}(\mathrm{bpm})$ & $3 \pm 16$ & $4 \pm 23$ & 0.950 & $0 \pm 21$ & $3 \pm 15$ & 0.442 \\
\hline \multicolumn{7}{|l|}{$\Delta$ Left Ventricular } \\
\hline ESV (ml) & $3 \pm 16$ & $0 \pm 15$ & 0.537 & $4 \pm 22$ & $2 \pm 22$ & 0.696 \\
\hline $\mathrm{EDV}(\mathrm{ml})$ & $9 \pm 26$ & $-8 \pm 24$ & 0.035 & $3 \pm 33$ & $0 \pm 29$ & 0.637 \\
\hline $\mathrm{SV}(\mathrm{ml})$ & $6 \pm 16$ & $-8 \pm 17$ & 0.009 & $-1 \pm 19$ & $-2 \pm 16$ & 0.725 \\
\hline $\mathrm{EF}(\%)$ & $1 \pm 5$ & $-2 \pm 6$ & 0.157 & $-1 \pm 6$ & $-1 \pm 7$ & 0.770 \\
\hline \multicolumn{7}{|l|}{$\Delta$ Right Ventricular } \\
\hline $\mathrm{ESV}(\mathrm{ml})$ & $4 \pm 20$ & $-12 \pm 13$ & 0.004 & $-1 \pm 22$ & $-8 \pm 27$ & 0.116 \\
\hline $\mathrm{EDV}(\mathrm{ml})$ & $12 \pm 23$ & $-18 \pm 24$ & $<0.001$ & $0 \pm 31$ & $-8 \pm 27$ & 0.223 \\
\hline $\mathrm{SV}(\mathrm{ml})$ & $8 \pm 16$ & $-7 \pm 19$ & 0.009 & $1 \pm 17$ & $0 \pm 17$ & 0.820 \\
\hline $\mathrm{EF}(\%)$ & $1 \pm 7$ & $1 \pm 7$ & 0.889 & $1 \pm 7$ & $2 \pm 7$ & 0.418 \\
\hline
\end{tabular}

$M A P$ Mean Arterial Pressure, HR Heartrate, ESV End Systolic Volume, EDV End Diastolic Volume, SV Stroke Volume, EF Ejection Fraction Plus-minus values are means $\pm \mathrm{SD}$

tan on mean arterial blood pressure (MAP) was observed in HI patients.

Changes in left and right ventricular volumes and function in the entire cohort were comparable between the losartan group and the control group. Furthermore, analysis of losartan only therapy or a combination of losartan and $\beta$-blocker therapy on right or left ventricular volumes, heart rate or EF in this subgroup rendered similar results.

\section{Blood pressure and ventricular function}

In the entire cohort, after 3 year's treatment losartan significantly reduced MAP by $7 \pm 10 \mathrm{~mm} \mathrm{Hg}$ when compared with baseline $(p<0.001)$, and differed significantly from change in MAP compared with the control group. At baseline, no significant correlation was found between MAP and ESV, EDV or SV $(r=0.064, p=0.426 ; r=-0.014$, $p=0.860 ; r=-0.108, p=0.176$; respectively). In losartan treated patients, there was also no significant correlation between change in MAP and change in ESV, EDV or SV $(r=-0.117, p=0.326 ; r=-0.060, p=0.615 ; r=0.023$, $p=0.847$; respectively).

\section{Discussion}

To our knowledge, this is the first large follow-up study to assess the effect of losartan on biventricular function in both $\mathrm{HI}$ and DN asymptomatic MFS patients using CMR. In this study, LV-EF was lower in MFS patients with a DN FBN1 mutation than in those with an HI FBN1 mutation. Losartan therapy increased EDV and SV, independent of change in blood pressure only in MFS patients with an HI FBN1 mutation. Furthermore, no beneficial effect of losartan on cardiac systolic function in the study group as a whole could be demonstrated.

MFS is caused by mutations in the $F B N 1$ gene, leading to $\mathrm{HI}$ or DN mutations of the fibrillin-1 protein [1]. Both mutations indirectly lead to increased levels of TGF- $\beta$, which is correlated to aortic disease in MFS [17]. However, TGF$\beta$ most likely also plays a role in myocardial fibrosis [25, 26]. Furthermore, blocking of TGF- $\beta$ in both rat studies involving pressure-overloaded hearts and mice studies involving hypertrophic hearts, prevented myocardial fibrosis and diastolic dysfunction [27-29].

Losartan, an angiotensin II receptor type 1 inhibitor, is known to reduce both TGF- $\beta$ signalling and blood pressure. However, we demonstrated that (change of) mean arterial blood pressure did not correlate with (change in) ventricular dimensions. Therefore, the effect of losartan on ventricular dimensions is not merely blood pressure-related. a possible explanation for the significant difference in baseline ventricular function and response to losartan between $\mathrm{HI}$ and DN might therefore be due to a difference in TGF- $\beta$ levels. This is in line with an earlier study by Franken et al., who demonstrated that losartan therapy significantly reduced the aortic root dilatation rate in the HI, whereas only a modest, insignificant reduction was found in DN MFS patients [17]. Furthermore, HI patients have a reduced but functionally normal fibrillin-1 protein, while the DN patient group is more heterogeneous since they display a broad spectrum of dysfunctional fibrillin-1 proteins, possibly explaining the variable response to losartan in the DN group. In addition, reduced ventricular function in DN patients might also be 
Fig. 2 Box plot showing change in left and right ventricular stroke volume between control and losartan group in Marfan patients with a $F B N 1$ mutation leading to haploinsufficiency $(n=43)$ or to a dominant-negative effect $(n=92)$. Abbreviations: $S V$ denotes stroke volume, $L V$ denotes left ventricle, $R V$ denotes right ventricle. Boxes indicate median with interquartile range. Error bars indicate upper 90 percentile and lower 10 percentile limits

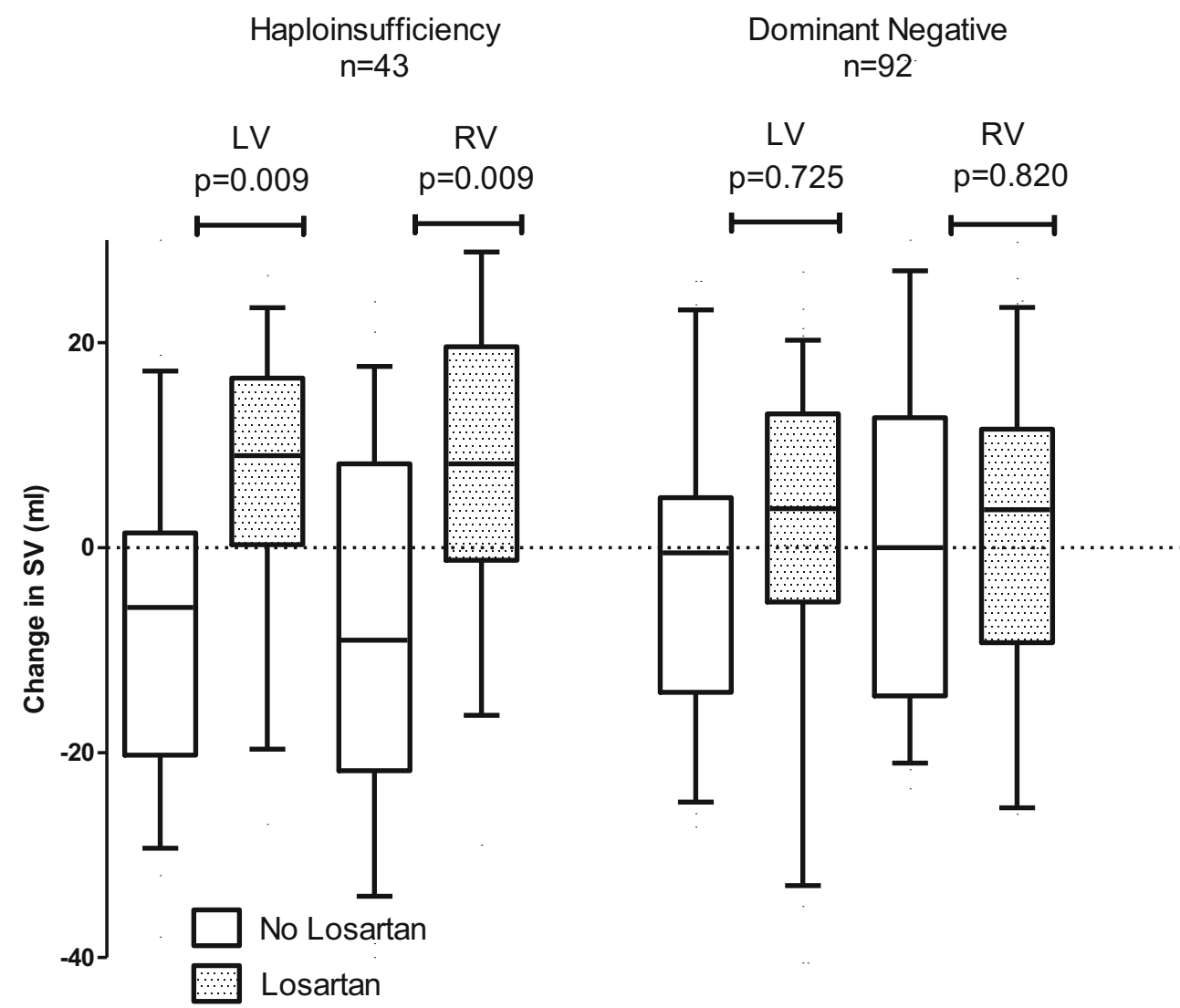

the result of a disorganised ECM due to the dysfunctional fibrillin-1 proteins [30, 31].

In conclusion, systolic ventricular function in MFS patients with a DN FBN1 mutation was slightly, but significantly reduced compared with patients with an HI FBNI mutation. In MFS patients with an FBNI mutation leading to $\mathrm{HI}$, losartan increased both EDV and SV, independent of change in blood pressure, suggesting a beneficial effect on left and right ventricular filling properties. No beneficial effect of losartan on ventricular function in the entire MFS cohort could be demonstrated.

\section{Limitations}

Our patients were still relatively young and mainly asymptomatic. Furthermore, the clinical implications of our findings are limited. However, the occurrence of ventricular dysfunction will most likely increase due prolonged longevity in MFS as a result of prophylactic aortic root replacement and improved medicinal therapy. Other limitations are the limited sample size, lack of TGF- $\beta$ levels and relatively small subgroups. Although losartan appeared to increase EDV in HI patients, thereby suggesting a beneficial effect on left and right ventricular filling properties, absolute diastolic filling properties were not assessed by CMR.

Acknowledgements This work is funded by a grant from the Netherlands Heart Foundation (2008B115) and supported by the Interuniversity Cardiology Institute of the Netherlands (ICIN). The work was carried out in the context of the Parelsnoer Institute (PSI). PSI is part of and funded by the Netherlands Federation of University Medical Centers.

Funding This work has been funded by a grant from the Dutch Heart Association (2008B115) and supported by ICIN.

Open Access This article is distributed under the terms of the Creative Commons Attribution 4.0 International License (http:// creativecommons.org/licenses/by/4.0/), which permits unrestricted use, distribution, and reproduction in any medium, provided you give appropriate credit to the original author(s) and the source, provide a link to the Creative Commons license, and indicate if changes were made.

\section{References}

1. Robinson PN, Arteaga-Solis E, Baldock C, et al. The molecular genetics of Marfan syndrome and related disorders. J Med Genet. 2006;43:769-87.

2. Habashi JP, Doyle JJ, Holm TM, et al. Angiotensin II type 2 receptor signaling attenuates aortic aneurysm in mice through ERK antagonism. Science. 2011;332:361-5. 
3. den Hartog AW, Franken R, Zwinderman AH, et al. The risk for type B aortic dissection in Marfan syndrome. J Am Coll Cardiol. 2015;65:246-54.

4. Nagashima H, Sakomura Y, Aoka Y, et al. Angiotensin II type 2 receptor mediates vascular smooth muscle cell apoptosis in cystic medial degeneration associated with Marfan's syndrome. Circulation. 2001;104(12 Suppl 1):I282-I7.

5. Groenink M, den Hartog AW, Franken R, et al. Losartan reduces aortic dilatation rate in adults with Marfan syndrome: a randomized controlled trial. Eur Heart J. 2013;34:3491-500.

6. Milleron O, Arnoult F, Ropers J, et al. Marfan Sartan: a randomized, double-blind, placebo-controlled trial. Eur Heart J. 2015;36:2160-6.

7. Lacro RV, Dietz HC, Sleeper LA, et al. Atenolol versus losartan in children and young adults with Marfan's syndrome. N Engl J Med. 2014;371:2061-71.

8. de Witte $\mathrm{P}$, Aalberts JJ, Radonic $\mathrm{T}$, et al. Intrinsic biventricular dysfunction in Marfan syndrome. Heart. 2011;97:2063-8.

9. Aalberts JJ, van Tintelen JP, Meijboom LJ, et al. Relation between genotype and left-ventricular dilatation in patients with Marfan syndrome. Gene. 2014;534:40-3.

10. de Backer JF, Devos D, Segers P, et al. Primary impairment of left ventricular function in Marfan syndrome. Int $\mathrm{J}$ Cardiol. 2006;112:353-8.

11. Meijboom LJ, Timmermans J, van Tintelen JP, et al. Evaluation of left ventricular dimensions and function in Marfan's syndrome without significant valvular regurgitation. Am J Cardiol. 2005;95:795-7.

12. Alpendurada F, Wong J. Kiotsekoglou a et al. Evidence for Marfan cardiomyopathy. Eur J Heart Fail. 2010;12:1085-91.

13. Radonic T, de Witte P, Baars MJ, Zwinderman AH, Mulder BJ, Groenink M. Losartan therapy in adults with Marfan syndrome: study protocol of the multi-center randomized controlled COMPARE trial. Trials. 2010;11:3.

14. de Paepe A, Devereux RB, Dietz HC, Hennekam RC, Pyeritz RE. Revised diagnostic criteria for the Marfan syndrome. Am J Med Genet. 1996;62:417-26.

15. Loeys BL, Dietz HC, Braverman AC, et al. The revised Ghent nosology for the Marfan syndrome. J Med Genet. 2010;47(7): 476-85.

16. Bonow RO, Carabello BA, Chatterjee K, et al. Focused update incorporated into the ACC/AHA 2006 guidelines for the management of patients with valvular heart disease: a report of the American College of Cardiology/American Heart Association task force on practice guidelines (writing committee to revise the 1998 guidelines for the management of patients with valvular heart disease): endorsed by the Society of Cardiovascular Anesthesiologists, Society for Cardiovascular Angiography and Interventions, and Society of Thoracic Surgeons. Circulation. 2008;118(15):e523-e661.

17. Franken R, den Hartog AW, Radonic T, et al. Beneficial outcome of Losartan therapy depends on type of FBN1 mutation in Marfan syndrome. Circ Cardiovasc Genet. 2015;383-8. doi:10.1161/ CIRCGENETICS.114.000950
18. Liu W, Schrijver I, Brenn T, Furthmayr H, Francke U. Multi-exon deletions of the FBN1 gene in Marfan syndrome. BMC Med Genet. 2001;2:11.

19. Dietz HC, McIntosh I, Sakai LY, et al. Four novel FBN1 mutations: significance for mutant transcript level and EGF-like domain calcium binding in the pathogenesis of Marfan syndrome. Genomics. 1993;17:468-75.

20. Milewicz DM, Grossfield J, Cao SN, Kielty C, Covitz W, Jewett T. A mutation in FBN1 disrupts profibrillin processing and results in isolated skeletal features of the Marfan syndrome. J Clin Invest. 1995;95:2373-8.

21. Hollister DW, Godfrey M, Sakai LY, Pyeritz RE. Immunohistologic abnormalities of the microfibrillar-fiber system in the Marfan syndrome. N Engl J Med. 1990;323:152-9.

22. Schrijver I, Liu W, Odom R, et al. Premature termination mutations in FBN1: distinct effects on differential allelic expression and on protein and clinical phenotypes. Am J Hum Genet. 2002;71:223-37.

23. Schrijver I, Liu W, Brenn T, Furthmayr H, Francke U. Cysteine substitutions in epidermal growth factor-like domains of fibrillin-1: distinct effects on biochemical and clinical phenotypes. Am J Hum Genet. 1999;65:1007-20.

24. Hudsmith LE, Petersen SE, Francis JM, Robson MD, Neubauer S. Normal human left and right ventricular and left atrial dimensions using steady state free precession magnetic resonance imaging. J Cardiovasc Magn Reson. 2005;7:775-82.

25. Lijnen PJ, Petrov VV, Fagard RH. Induction of cardiac fibrosis by transforming growth factor-beta(1). Mol Genet Metab. 2000;71:418-35.

26. Dobaczewski M, Chen W, Frangogiannis NG. Transforming growth factor (TGF)-beta signaling in cardiac remodeling. J Mol Cell Cardiol. 2011;51:600-6.

27. Kuwahara F, Kai H, Tokuda K, et al. Transforming growth factor-beta function blocking prevents myocardial fibrosis and diastolic dysfunction in pressure-overloaded rats. Circulation. 2002;106:130-5.

28. Blyszczuk P, Muller-Edenborn B, Valenta T, et al. Transforming growth factor-beta-dependent Wnt secretion controls myofibroblast formation and myocardial fibrosis progression in experimental autoimmune myocarditis. Eur Heart J. 2016; doi:10.1093/eurheartj/ ehw116.

29. Rikitake Y, Oyama N, Wang CY, et al. Decreased perivascular fibrosis but not cardiac hypertrophy in ROCK1+/- haploinsufficient mice. Circulation. 2005;112:2959-65.

30. Cook JR, Carta L, Benard L, et al. Abnormal muscle mechanosignaling triggers cardiomyopathy in mice with Marfan syndrome. J Clin Invest. 2014;124:1329-39.

31. Pinto YM, Pinto-Sietsma SJ, Philipp T, et al. Reduction in left ventricular messenger RNA for transforming growth factor beta(1) attenuates left ventricular fibrosis and improves survival without lowering blood pressure in the hypertensive TGR(mRen2)27 Rat. Hypertension. 2000;36:747-54. 